This article is licensed under the Creative Commons Attribution-NonCommercial 4.0 International License (CC BY-NC) (http://www.karger.com/Services/OpenAccessLicense). Usage and distribution for commercial purposes requires written permission.

\title{
A Case of Endoscopic Mucosal Resection of Carcinoma in Adenoma at the Minor Duodenal Papilla
}

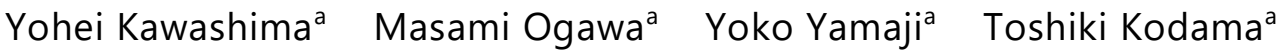 \\ Masashi Yokota $^{a} \quad$ Aya Kawanishi $^{a} \quad K e n i c h i$ Hirabayashi ${ }^{b}$ Tetsuya Mine ${ }^{a}$ \\ aDepartment of Gastroenterology, Tokai University School of Medicine, Isehara, Japan; \\ ${ }^{b}$ Department of Pathology, Tokai University School of Medicine, Isehara, Japan
}

\section{Keywords}

Minor duodenal papilla Adenocarcinoma in adenoma - Endoscopic mucosal resection

\begin{abstract}
Here, we describe a case of minor papillary adenocarcinoma in adenoma that was treated with endoscopic mucosal resection (EMR). In a 67-year-old woman, sigmoid colon cancer was incidentally detected on preoperative upper gastrointestinal endoscopy. Endoscopy revealed a slightly elevated lesion at the minor duodenal papilla. The findings of a histopathologic examination were suggestive of adenocarcinoma. Computed tomography and magnetic resonance images identified a minute tumor, whereas endoscopic ultrasonography revealed that the tumor did not spread to the pancreas. We performed EMR of this lesion. There were no complications, and relapse has not occurred in 3 years. Cases of minor papillary adenocarcinoma treated with EMR are quite rare.

(C) 2019 The Author(s)

Published by S. Karger AG, Basel
\end{abstract}




\section{Case Reports in Oncology}

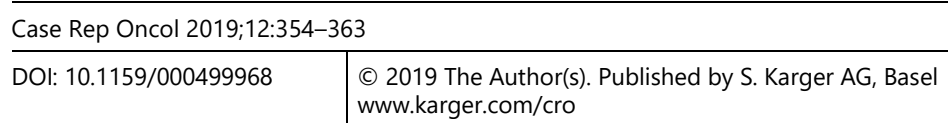

Kawashima et al:: A Case of Endoscopic Mucosal Resection of Carcinoma in Adenoma at the Minor Duodenal Papilla

\section{Introduction}

Tumors of the minor duodenal papilla are quite rare. We experienced a case of minor papillary adenocarcinoma in adenoma that was successfully completely resected under endoscopy; in addition, relapse has not occurred in more than 3 years. Here, we report the case and discuss the relevant literature.

\section{Case Report}

A 67-year-old Japanese woman was admitted to our hospital with a duodenal tumor that was incidentally detected on upper gastrointestinal endoscopy for the preoperative examination of sigmoid colon cancer. Endoscopy revealed a slightly elevated lesion at the minor papilla. Histopathologic examination of the biopsy performed by the previous doctor revealed class IV disease. She had no specific symptoms, and there were no abdominal findings on physical examination. The patient's medical history was sigmoid colon cancer and hypertension. Her family history was unremarkable. Results of laboratory tests, including pancreatic tumor markers, were normal (Table 1). Ultrasonography (US) failed to detected this lesion. The main pancreatic duct and bile duct were not dilated. Abdominal computed tomography (CT) revealed a $1.0-\mathrm{cm}$-sized enhancing mass in the minor duodenal papilla with no apparent distant metastasis (Fig. 1). Magnetic resonance cholangiopancreatography showed low intensity on a T1-weighted image and no dilation of the main pancreatic duct or bile duct (Fig. 2). Endoscopic US (EUS) detected a hypoechoic lesion in the submucosal layer (12 $\mathrm{mm}$ in diameter). EUS clearly showed the muscle layer; thus, we determined that the tumor did not invade the muscle layer (Fig. 3). Endoscopic retrograde pancreatography findings were normal (Fig. 4). We attempted to evaluate the degree of tumor progression using intraductal US (IDUS) through the minor duodenal papilla; however, it was difficult to insert and thus could not be evaluated. Endoscopic sphincterotomy (EST) was performed to enable histological examination of the deeper layer and IDUS insertion; however, histological results were atypical and IDUS insertion remained difficult. A histological examination was performed before treatment, whereas biopsies from the minor papilla demonstrated the histology of adenoma with mild atypia.

We determined that the tumor was not invasive; additionally, the patient and her family did not request surgical treatment. Therefore, we performed endoscopic mucosal resection (EMR) after obtaining appropriate written informed consent (Fig. 5). First, we performed marking using argon plasma coagulation around the tumor. Next, the lesion was completely elevated by a submucosal injection of saline and then removed using a snare. The excised specimens were collected using a net. No adverse events, such as bleeding or perforation, were observed.

Papillary proliferation of atypical columnar epithelium cells was observed from within the pancreatic duct of the minor duodenal papilla to the duodenum's surface. Atypical cells had enlarged nuclei with nucleoli. Structural heteromorphism was conspicuous. In the same site, MIB-1 was more frequently positive than the surrounding tissue, while p53 was weakly positive. On immunostaining, MUC-5AC was positive in the surface layer and MUC- 6 was positive in the deep layer, suggestive of a gastric-type cancer. Histopathologic examination 


\section{Case Reports in Oncology}

Case Rep Oncol 2019;12:354-363

DOI: $10.1159 / 000499968$

C 2019 The Author(s). Published by S. Karger AG, Basel www.karger.com/cro

Kawashima et al.: A Case of Endoscopic Mucosal Resection of Carcinoma in Adenoma at the Minor Duodenal Papilla

revealed adenocarcinoma in adenoma and confirmed complete resection (Fig. 6). We followed up with yearly upper gastrointestinal endoscopy and CT. Three years after EMR, the patient remains asymptomatic without signs of recurrence.

\section{Discussion}

The minor duodenal papilla is usually situated in the second portion of the duodenum approximately and about $2-3 \mathrm{~cm}$ proximal to the major papilla. The minor duodenal papilla is smaller than the major papilla, at approximately $4 \mathrm{~mm}$. It exists as an orifice of the accessory pancreatic duct from the dorsal pancreas but often degenerates in the growth process. The patency of the minor papilla has been addressed in numerous studies [1, 2] at a rate of 12 $82 \%$. One report showed that the patency rate was not related to the size of the minor papilla, whereas the patency rate increased as the distance from the main papilla decreased [3].

Tumors of the minor papilla are rare. Almost all cases of the minor papilla are reported as adenoma [4], carcinoid [5], or somatostatinoma [6]. Adenocarcinoma and adenocarcinoma in adenoma are quite rare. Surgical resection is considered the primary therapy for minor and major papillary adenocarcinoma $[7,8]$. The indication for endoscopic resection of major papillary tumor is adenoma, which is considered a case without pancreatic duct and bile duct infiltration. Treatment reports of adenoma applying this have been found also in minor papillary tumors; however, there are two reports of cancer $[9,10]$. Both cases were asymptomatic and were identified on screening upper gastrointestinal endoscopy. If the patient had symptoms such as abdominal pain, the diagnosis could be an anatomical abnormality-like pancreas divisum or an advanced case with comorbid jaundice, and such symptoms do not appear in normal minor papillary tumor.

The most important step in determining a treatment strategy involves distinguishing between benign and malignant tumors. It is difficult to increase biopsy quality and evaluate the extent of tumor invasion.

In our case, we performed multiple endoscopic examinations. The biopsy result by the previous doctor was class IV; however, in our hospital, biopsies from the minor papilla demonstrated the histology of adenoma with mild atypia, which was difficult to determine biopsy. Yamaguchi et al. [11] reported that the diagnosis of carcinoma by biopsy at the major papilla is considered to be $75 \%$ because it is difficult to rule out the presence of carcinoma in the deeper layers. However, previous EST may also impair biopsy accuracy. Bourgeois et al. [12] reported that biopsies conducted after sphincterotomy often provide necrotic and inconclusive material. A prospective study reported that sampling errors inherent to the biopsy technique increase only keep the sensitivity of biopsy of cancer owing to sphincterotomy from $21 \%$ to $37 \%$ [13]. Therefore, it may not be said that the diagnosis of benign or malignant tumor based on biopsy of the minor papilla is ineffective because the same result was obtained in this case.

In contrast, we thought that the evaluation of accurate staging of minor papillary tumors by EUS and IDUS is useful. Many reports stated that EUS and IDUS were useful for major papillary tumor staging and that IDUS is generally more accurate. Accurate staging by IDUS is reportedly 78-93\%, while that of EUS is $62-63 \%$ [14, 15]. Ito et al. [14] reported that there was a difference in the diagnostic rate because the use of EUS was more difficult for evaluating 
infiltration into the duodenal muscle layer. However, in the case of the minor papillary tumor that we experienced, we planned IDUS insertion and observation after performing EPST, but we could not insert the probe owing to obstruction of the accessory pancreatic duct because of the tumor and thus could not evaluate the progress. On the other hand, using EUS, it was possible to evaluate the infiltration into the muscular layer. The usefulness of IDUS in the major papilla is considered easy to operate because it can be inserted into the bile duct. Because scanning from the bile duct is impossible in minor papillary tumors, it is necessary to investigate the usefulness of IDUS and EUS for the minor papillary in the future.

Endoscopic resection is considered safer and less invasive for non-invasive minor papillary tumors that show no intraductal extension to the accessory pancreatic duct. Experience with more of these types of cases is needed to reach consensus regarding the optimal method for diagnosing and treating tumors of the duodenal minor papilla, and should be performed after obtaining sufficient informed consent for complications such as gastrointestinal perforation and acute pancreatitis.

\section{Acknowledgement}

In writing this research, I received guidance from Dr. Yoshiaki Kawaguchi, Visiting Professor at the Department of Gastroenterology, Tokai University Hospital (Kanagawa, Japan), and I would like to express my deep appreciation to him.

\section{Statement of Ethics}

The authors have no ethical conflicts to disclose.

\section{Disclosure Statement}

The authors have no conflicts of interest to declare.

\section{References}

1 Baldwin WM. The pancreatic ducts in man, together with a study of the microscopical structure of the minor duodenal papilla. Anat Rec. 1911;5(5):197-228.

2 Simkins S. Variations in the pancreatic ducts and the minor duodenal papilla. Am J Med Sci. 1931;182(5):626-39.

3 Kamisawa T, Tu Y, Egawa N, Sakaki N, Ishiwata J, Okamoto A. Size, location and patency of the minor duodenal papilla as determined by dye-injection endoscopic retrograde pancreatography. Dig Endosc. 2001;13(2):82-5.

4 Sugiyama M, Kimura W, Muto T, Yahagi N, Ichinose M, Miki K. Endoscopic resection of adenoma of the minor papilla. Hepatogastroenterology. 1999 Jan-Feb;46(25):189-92.

5 Noda Y, Watanabe H, Iwafuchi M, Furuta K, Ichihara N, Satoh M, et al. Carcinoids and endocrine cell micronests of the minor and major duodenal papillae. Their incidence and characteristics. Cancer. 1992;70:1825-33. 
Kawashima et al:: A Case of Endoscopic Mucosal Resection of Carcinoma in Adenoma at the Minor Duodenal Papilla

6 Borobia FG, Fabregat J, Jorba R, Poves I, Biondo S, Serrano T, et al. Exocrine pancreatic insufficiency caused by a somatostatinoma of the minor and major duodenal papilla in a patient with neurofibromatosis. Eur J Surg. 2001 Feb;167(2):154-6.

7 Yamao K, Ohhashi K, Furukawa T, Mizutani S, Matsumoto S, Banno T, et al. Primary carcinoma of the duodenal minor papilla. Gastrointest Endosc. 1998 Dec;48(6):634-6.

8 Takami K, Moriya T, Kamiga T, Abe T, Miseki T, Oku T, et al. Adenocarcinoma of the minor duodenal papilla: report of a case. Case Rep Gastroenterol. 2011 Apr;5(1):172-8.

9 Nomura S, Nakagawa H, Hirayama M, et al. Adenocarcinoma of minor duodenal papilla treated by endoscopic mucosal resection. Gastroenterol Endosc. 2016;58(9):1413-9.

10 Matsui T, Matsubayashi H, Hotta K, Sasaki K, Ito H, Ono H. A case of carcinoma in an adenoma of the duodenal minor papilla successfully treated with endoscopic mucosal resection. Endosc Int Open. 2016 Mar;4(3):E252-4.

11 Yamaguchi K, Enjoji M, Kitamura K. Endoscopic biopsy has limited accuracy in diagnosis of ampullary tumors. Gastrointest Endosc. 1990 Nov-Dec;36(6):588-92.

12 Bourgeois N, Dunham F, Verhest A, Cremer M. Endoscopic biopsies of the papilla of Vater at the time of endoscopic sphincterotomy: difficulties in interpretation. Gastrointest Endosc. 1984 Jun;30(3):163-6.

13 Menzel J, Poremba C, Dietl KH, Böcker W, Domschke W. Tumors of the papilla of Vater-inadequate diagnostic impact of endoscopic forceps biopsies taken prior to and following sphincterotomy. Ann Oncol. 1999 Oct;10(10):1227-31.

14 Ito K, Fujita N, Noda Y, Kobayashi G, Horaguchi J, Takasawa O, et al. Preoperative evaluation of ampullary neoplasm with EUS and transpapillary intraductal US: a prospective and histopathologically controlled study. Gastrointest Endosc. 2007 Oct;66(4):740-7.

15 Menzel J, Hoepffner N, Sulkowski U, Reimer P, Heinecke A, Poremba C, et al. Polypoid tumors of the major duodenal papilla: preoperative staging with intraductal US, EUS, and CT-a prospective, histopathologically controlled study. Gastrointest Endosc. 1999 Mar;49(3 Pt 1):349-57. 


\section{Case Reports in Oncology}

Case Rep Oncol 2019;12:354-363

DOI: $10.1159 / 000499968$

(c) 2019 The Author(s). Published by S. Karger AG, Basel www.karger.com/cro

Kawashima et al:: A Case of Endoscopic Mucosal Resection of Carcinoma in Adenoma at the Minor Duodenal Papilla

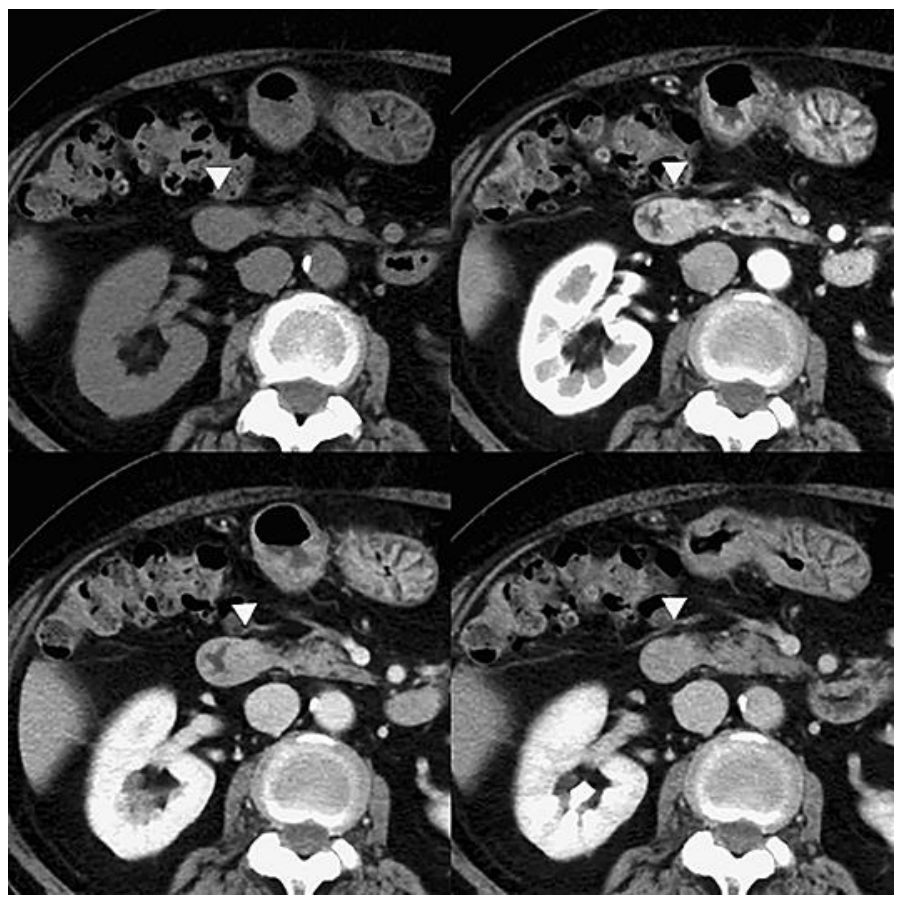

Fig. 1. Computed tomography showing a 10-mm-sized hypervascular tumor in the minor duodenal papilla. No dilation of the biliary and pancreatic ducts is apparent.

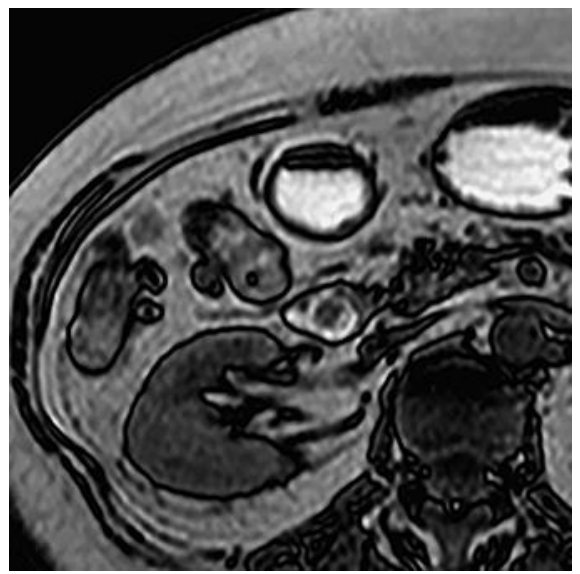

Fig. 2. T1-weighted magnetic resonance image showing lower tumor intensity and no dilation of the main pancreatic duct. 


\section{Case Reports in Oncology}

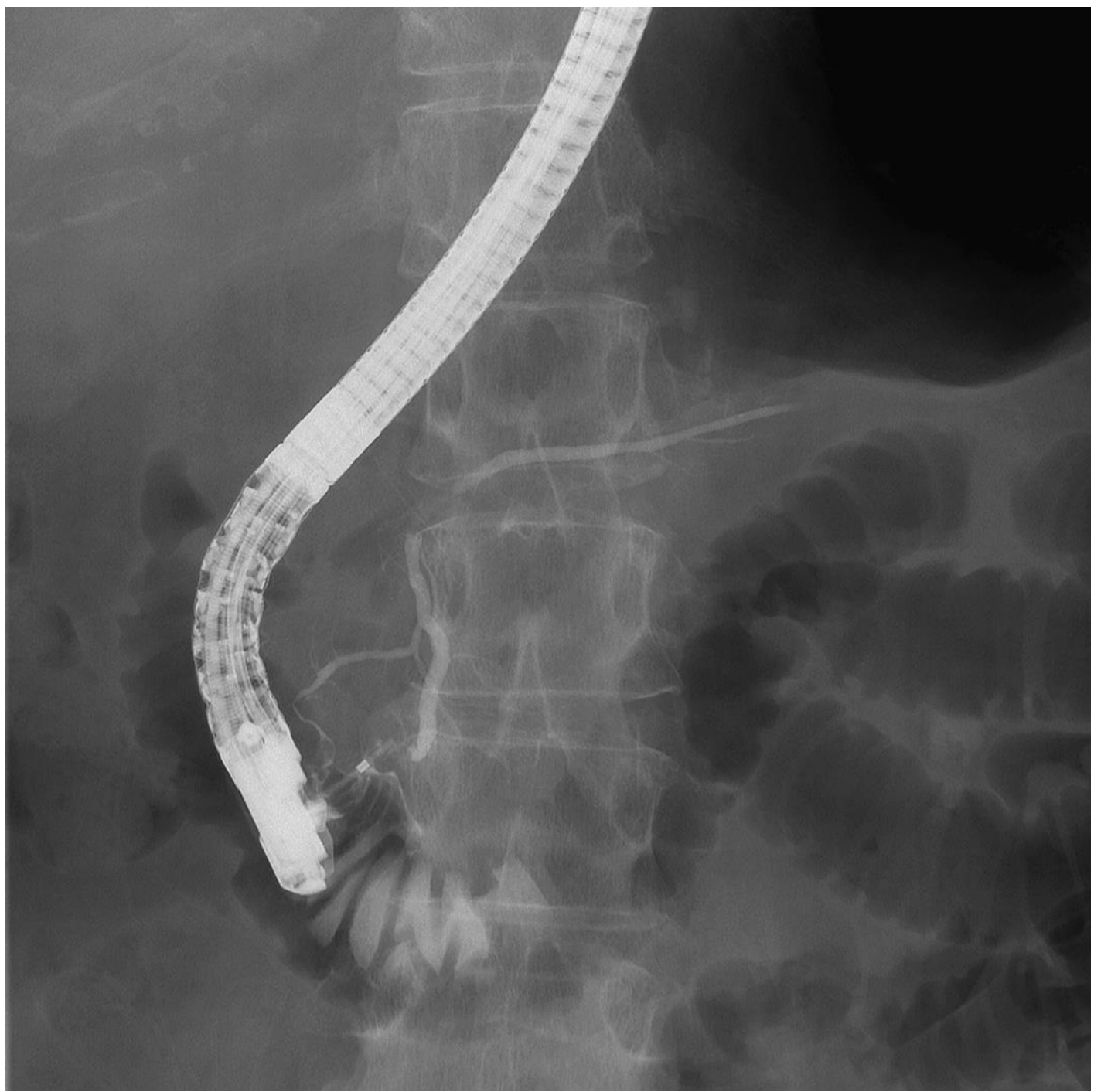

Fig. 3. Endoscopic retrograde cholangiopancreatography image of the major papilla was normal with no abnormalities such as dilation of the Wirsung duct or stenosis of the Santorini duct.

Kawashima et al:: A Case of Endoscopic Mucosal Resection of Carcinoma in Adenoma at the Minor Duodenal Papilla 


\section{Case Reports in Oncology}

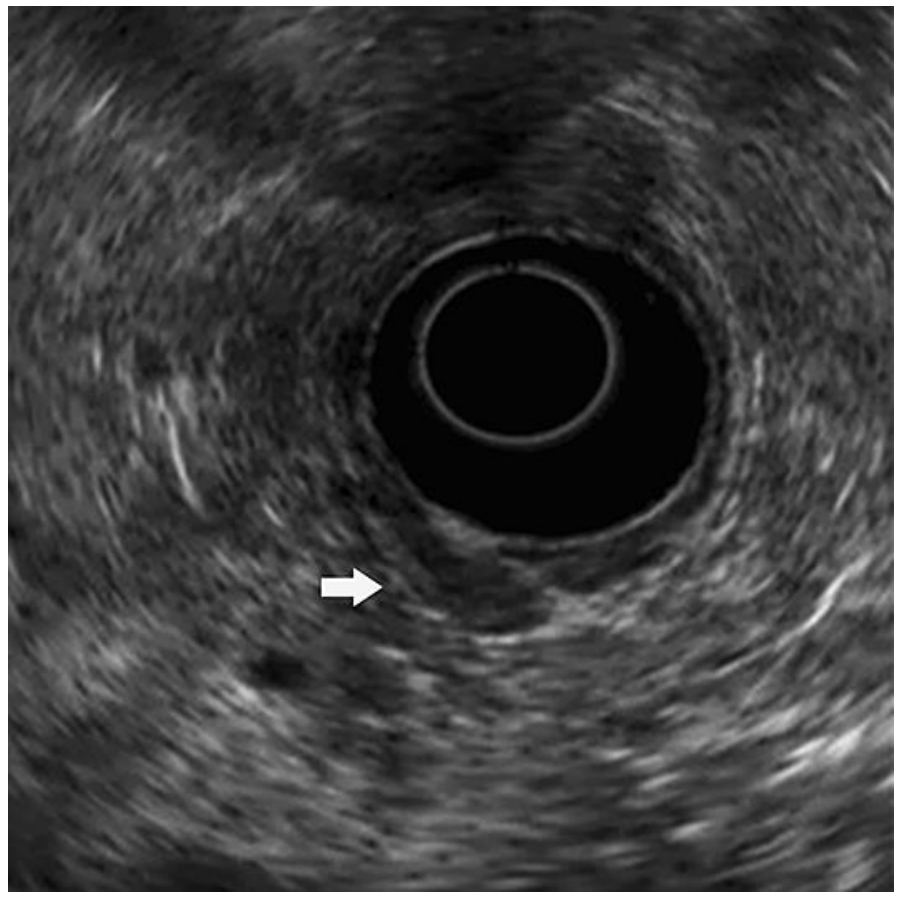

Fig. 4. Endoscopic ultrasound showing a hypoechoic mass in the submucosal layer at the minor duodenal papilla. No tumor invasion into the muscle layer was observed.

Kawashima et al.: A Case of Endoscopic Mucosal Resection of Carcinoma in Adenoma at

the Minor Duodenal Papilla

(c) 2019 The Author(s). Published by S. Karger AG, Basel www.karger.com/cro 


\section{Case Reports in Oncology}

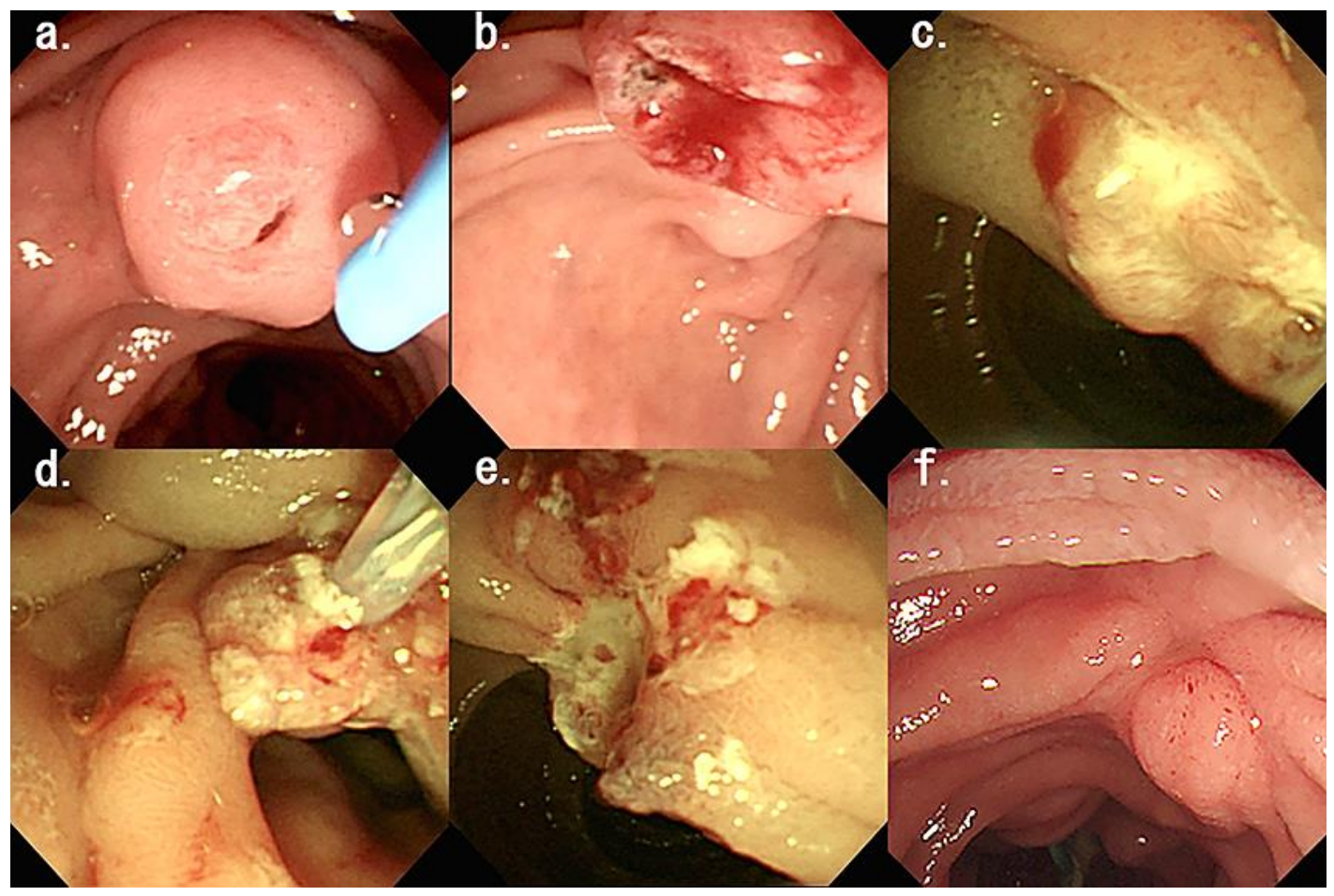

Fig. 5. a Image of side-viewing endoscopy. b After endoscopic sphincterotomy. c Submucosal injection of saline. $\mathbf{d}$ Electric snare ligation. e Ulcer after endoscopic mucosal resection. $\mathbf{f}$ Endoscopic findings 3 months after resection. 


\section{Case Reports in Oncology}

Case Rep Oncol 2019;12:354-363

DOI: $10.1159 / 000499968$ (c)

Kawashima et al: A Case of Endoscopic Mucosal Resection of Carcinoma in Adenoma at the Minor Duodenal Papilla

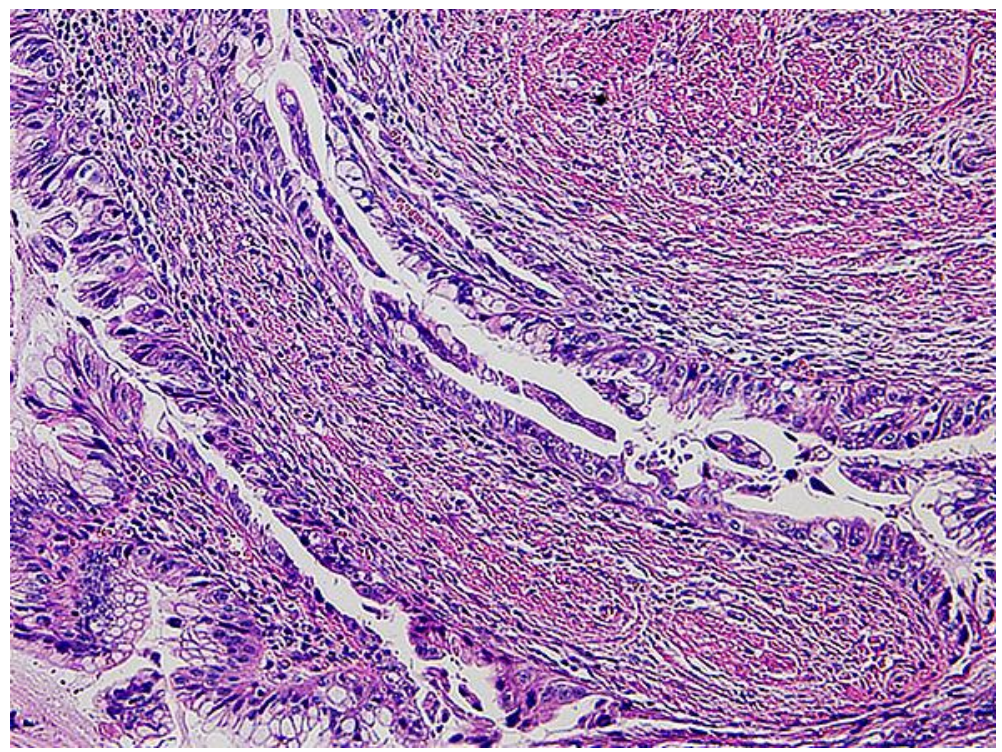

Fig. 6. Histopathology image (hematoxylin and eosin staining; magnification, $\times 100$ ).

Table 1. Laboratory data on admission

\begin{tabular}{llll}
\hline \multicolumn{2}{l}{ Complete blood count } & Glu & $106 \mathrm{mg} / \mathrm{dL}$ \\
$\mathrm{WBC}$ & $4,000 / \mu \mathrm{L}$ & $\mathrm{Amy}$ & $46 \mathrm{U} / \mathrm{L}$ \\
$\mathrm{Hb}$ & $13.8 \mathrm{mg} / \mathrm{dL}$ & $\mathrm{Cr}$ & $0.57 \mathrm{mg} / \mathrm{dL}$ \\
$\mathrm{Ht}$ & $40.2 \%$ & $\mathrm{BUN}$ & $9 \mathrm{mg} / \mathrm{dL}$ \\
$\mathrm{PLT}$ & $22.0 \times 10^{4} / \mu \mathrm{L}$ & $\mathrm{Na}$ & $148 \mathrm{mEq} / \mathrm{L}$ \\
& & $\mathrm{K}$ & $3.6 \mathrm{mEq} / \mathrm{L}$ \\
Biochemistry & & $\mathrm{Cl}$ & $108 \mathrm{mEq} / \mathrm{L}$ \\
$\mathrm{TP}$ & $8.2 \mathrm{~g} / \mathrm{dL}$ & $\mathrm{CRP}$ & $0.09 \mathrm{~g} / \mathrm{dL}$ \\
$\mathrm{Alb}$ & $4.6 \mathrm{~g} / \mathrm{dL}$ & $\mathrm{HbA} 1 \mathrm{c}$ & $5.3 \%$ \\
GOT & $48 \mathrm{U} / \mathrm{L}$ & & \\
GPT & $54 \mathrm{U} / \mathrm{L}$ & Serological examination \\
$\mathrm{LDH}$ & $213 \mathrm{U} / \mathrm{L}$ & $\mathrm{CEA}$ & $3.2 \mathrm{ng} / \mathrm{mL}$ \\
$\mathrm{ALP}$ & $214 \mathrm{U} / \mathrm{L}$ & $\mathrm{CA} 19-9$ & $12.2 \mathrm{U} / \mathrm{mL}$ \\
$\Gamma-\mathrm{GTP}$ & $43 \mathrm{U} / \mathrm{L}$ & & \\
\hline
\end{tabular}

